\title{
Non-human resistance in changes towards lean
}

\author{
Jostein Langstrand and Mattias Elg
}

\section{Linköping University Post Print}

N.B.: When citing this work, cite the original article.

Original Publication:

Jostein Langstrand and Mattias Elg, Non-human resistance in changes towards lean, 2012, Journal of Organizational Change Management, (25), 6, 853-866.

http://dx.doi.org/10.1108/09534811211280609

Copyright: Emerald http://www.emeraldinsight.com/

Postprint available at: Linköping University Electronic Press http://urn.kb.se/resolve?urn=urn:nbn:se:liu:diva-75353 


\title{
Non-human Resistance in Changes towards Lean
}

\author{
Jostein Langstrand \& Mattias Elg
}

\begin{abstract}
Purpose - The importance of social issues is well established in the literature on resistance to change. However, much can be gained by including physical objects in the analysis. Using actornetwork theory, this paper aims to explore the resistance of non-human actors in organizational change and contribute to an expanded understanding of resistance to change.
\end{abstract}

Design/methodology/approach - The article is based on a longitudinal case study of the introduction of Lean in a large Swedish manufacturing company. The empirical basis consists of interviews, observations and document studies. Actor-network theory is used as a theoretical lens to identify non-human resistance to change.

Findings - We propose that non-human actors can inhibit change through a lack of alignment with the overall change initiative. This may cause large variation in the interpretation of the proposed change and a lengthy process of construction and negotiation. The paper provides examples of four different types of non-human resistance that result from this lack of alignment.

Practical implications - We propose that change initiatives need to be aligned with existing practice and anchored in objects that are integrated in organizational routines. The four types of non-human resistance presented in the paper may be used as a checklist to reduce the risk of failure.

Originality/value - The predominant focus on social issues tends to disregard the impact of the physical environment in change processes. Actor-network theory and the inclusion of the physical environment will help to expand and improve our understanding of resistance to change.

Keywords - Change, Resistance, Lean Production, Actor-Network Theory

Paper type - Research paper

\section{Introduction}

According to Beer and Nohria (2000), as many as $70 \%$ of all organizational change initiatives fail. In a member survey, the Lean Enterprise Institute (LEI) found that more than $36 \%$ of the respondents attributed change failure to middle management resistance. Along with employee resistance and supervisor resistance, these were considered three of the four most significant obstacles to implementing lean (LEI, 2007).

In an overview of the research on resistance to change, Ford et al. (2002) show that resistance is usually ascribed to some kind of threat perceived by individuals in organizational settings. From this perspective, resistance is an outcome of social construction.

We propose that resistance is a function of the socially constructed reality in which someone lives (...); it is the nature of this reality that gives resistance its particular form, mood, and flavor. (Ford et al. 2002, p.106)

According to Macrì et al. (2002) managers have a central role in this construction process and can prevent resistance by conveying a positive image of the change. Surely, actors' perceptions of a change initiative are likely to be influenced by management; but organizational practice is deeply embedded in various systems and procedures that are equally - if not more - influential (Orlikowski, 2000; Volkoff et al., 2007). 
While Ford et al. (2002) view reality as constructed through human interaction (and mainly discourse), we would like to use the quote above to fuel a different argument: namely that our perceptions of reality are constructed through interaction with humans as well as our physical environment. According to Macrì et al. (2002), organizational change has traditionally been viewed from two different perspectives: either as a result of interaction with the environment or as a direct alteration of behavioral patterns. Following Latour (2005), we wish to combine these two perspectives and see organizations as socio-technical systems that consist of human and non-human actors and their interactions.

While the importance of social issues is well established in the literature on organizational change and resistance, we argue that it is necessary to be open to a greater variation in the sources of resistance (cf. Jermier et al., 1994). We believe much can be gained from including the physical environment in the analysis. The purpose of this paper is to explore the resistance of non-human actors in organizational change and contribute to an expanded perspective on resistance to change. The main research question that we address is how non-human actors influence, and sometimes resist, organizational change processes.

In order to answer this question, we will begin with a theoretical discussion on the relationship between non-human actors and organizational change. The paper will then continue with empirical examples that illustrate how non-human resistance can manifest itself.

\section{A socio-technical perspective on change}

This paper is largely based on the perspective presented by Feldman (2003), albeit with some modifications. According to Feldman there is a reciprocal relationship between organizational routines and people's understanding of how the organization operates; people's understandings guide their practice, which in turn creates and reinforces their understandings. While we agree with this perspective, we argue that the physical context and artifacts that tie into organizational practice mediate both understandings about the organization as well as influence the routines directly (cf. Hutchins, 1993; Suchman, 1987; Volkoff et al., 2007).

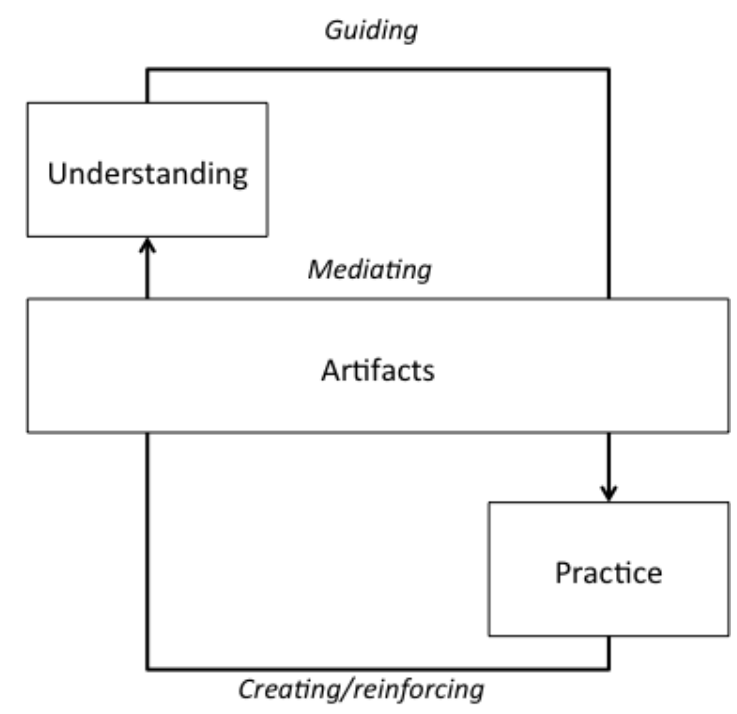

Figure 1 Organizational systems and artifacts as mediators of organizational understanding and practice (adapted from Feldman, 2003).

Organizations may be viewed as containing a number of interdependent and interlocking routines, all of which influence people's way of thinking as well as their 
behavior (Feldman, 2003). As stated by Feldman and Pentland (2003), "routines are enmeshed in far-reaching, complex, tangled webs of interdependence" (p. 104). However, a practitioner of one routine usually does not observe the other routines directly, but only the outcomes or artifacts of these (Feldman and Pentland, 2003). In other words, the artifacts that are generated by surrounding routines largely shape understandings of the organization (Hutchins, 1993). As argued by Latour (1992), these artifacts often have a preserving and stabilizing effect on behavior. Similarly, the introduction of new artifacts can also be an effective method for communicating a certain meaning and inspire a change of routines (Lave and Wenger, 1991; Gherardi and Nicolini, 2000). Several authors address the issue of how artifacts influence human actions (Latour, 1992; Orlikowski, 2000; Volkoff et al., 2007). This influence is a central issue within Actor-Network Theory (ANT), where a key point of interest is how these entities interact and together facilitate stabilization and fulfillment of action programs (Callon, 1986; Latour, 1987). Engaging in a project such as introducing Lean in an organization could, in ANT-terms, be seen as an attempt to enforce an action program.

The strength of an action program is determined by the degree of alignment between the interests of actors in the network (Callon and Latour, 1981; Callon, 1986; Latour, 1987). Artifacts contribute to the creation and stabilization of networks, supporting and enforcing certain types of behavior; and the stronger support an actor can mobilize from other actors (human or non-human), the stronger the action program (Callon and Latour, 1981; Hanseth and Monteiro, 1997; Latour, 1987). As non-human actors have no voices of their own, their 'interests' are communicated through inscriptions in various artifacts (Latour, 1992). Following Latour, an artifact can communicate a message or encourage a certain course of action through its physical appearance or conventions that are associated with that artifact. In such a case, the corresponding interest, message or action program is inscribed in that artifact (Latour, 1987; Latour and Woolgar, 1986). A non-human actor can, through these inscriptions, influence behavior, and thereby contribute to reinforce the associated action program (Hanseth and Monteiro, 1997).

Although it may be difficult to resist an action program altogether, actors are not left entirely at the mercy of the inscriptions. According to Callon and Latour (1981), power lies in interpretation and translation; in other words, every actor basically has the same power. According to Latour, all actors are free to further translate an idea, regardless of its origin.

...the spread in time and space of anything - claims, orders, artifacts, goods - is in the hands of people; each of these people may act in many different ways, letting the token drop, or modifying it, or deflecting it, or betraying it, or adding to it, or appropriating it. (Latour, 1986, p. 267)

In the same way as actors have the power to contest a certain message, they also have the power to contest an action program and create contrary programs - so called antiprograms (Akrich and Latour, 1992; Latour, 1986). Thus, the strength of an inscription and its associated action program depends on what the receiver does with it (Latour, 1992).

Eventually, provided that a network succeeds in promoting its action program, interests and inscriptions will be aligned to the extent that the action program is assimilated into practice and taken for granted by enrolled actors.

The assembly of disorderly and unreliable allies is thus slowly turned into something that closely resembles an organized whole. When such cohesion is obtained we at last have a black box. (Latour, 1987, pp. 130-131)

At this point, the network is punctualized (Callon and Law, 1997), and the course of action proposed by the action program is taken for granted by the enrolled actors and becomes a 'black box' (Latour, 1987). In these cases, the receiver is left with no viable 
alternative other than adhering to the action program inscribed in the black box; the inscription becomes a prescription. This prescription reduces the possibility for further translations and causes the network to stabilize.

\section{Introduction to the case}

The empirical basis of this article is a longitudinal study, during the period 2007 through 2010, of the introduction of Lean Production in a large manufacturing company in Sweden. Our case company, here given the pseudonym HiTech Inc, is a producer of advanced machinery for industrial applications. The case study at hand is focused on the production organization of the company, which is distributed across three different factory floors, each comprising up to eight production units. The production organization employs about 500 people.

\section{Methodology}

The study at hand has been done within the Helix VINN Excellence centre at Linköping University. Helix has formed a partnership with about twenty organizations that take part in different research projects. One of these partner organizations is HiTech Inc. In this study we use a prospective longitudinal case design. The merit of this approach is that it enables the researcher to gain in-depth knowledge about processes and events that unfold over time (Pettigrew, 1985; Van de Ven et al., 2000). Prospective approaches, in comparison with retrospective studies, reduce risks of bias for respondents recalling specific events and influence on change outcome (Van de Ven et al. 2000). The study comprises several sources of information, such as participation in meetings and direct observation of operative work. Inspired by Barley (1990), the study is done in two phases.

In phase one, a series of retrospective interviews record the events prior to the start of the study and provide an overview of the change process. Twenty respondents have been selected from across the entire organization in order to trace a complete branch from top to bottom in the hierarchy. In order to get a diversified account of the initial change process, and thereby increase the internal validity of the study, two different sections of production have been studied. The respondents were asked to freely describe how they first encountered Lean and how they experienced the change effort. Following Isabella (1990), this strategy is based on a notion that the respondents themselves determine critical events in the change process.

Events like those of interest here unbalance established routines and evoke conscious thought on the part of organizational members by their very nature. In so doing, they signal "common breakpoints" for the perception of change [...]. Because these events make a difference in people's thought and action, they are "key events" in the eyes of organizational participants. (Isabella, 1990, p.11)

During the interviews, it was necessary to be sensitive to recurring themes or potentially important topics (Silverman, 2006). Upon identification of such 'common breakpoints', for instance issues pertaining to the introduction of specific Lean techniques, respondents were asked to elaborate.

In the second phase, a prospective approach is used with the ambition to catch the changes 'on the fly' through contextual interviews and observations. Here, with the purpose to dig deeper into the details of the change initiative, focus has been on the production organization. In this phase, the researchers have worked closely with a group of ten respondents, attending meetings, performing recurring interviews and observing the operative work. The interviews in this phase were more structured than the initial ones. Inspired by Van de Ven and Poole (1990), an interview guide was 
created to cover changes in five different categories: ideas, people, transactions, context (internal/external) and results.

In total, the study covers a total of 46 interviews with 30 respondents. The interviews were performed with single respondents and ranged from about 45 to 90 minutes. All interviews were recorded and transcribed. In addition, a number of internal documents have been collected and studied. Through the combination of retrospective and prospective methods, the study thereby covers the period from 2003 to 2010 .

Employing an ANT perspective, we have analyzed the empirical data and aimed to identify the most important non-human actors and determine how they influence the change process. The analysis has been performed on several different levels, as discussed by Miles and Huberman (1994). First, a rough conceptual framework was produced, based on theories of change and translation. The framework was then adapted into a coding system, which was used to highlight elements in the interview transcripts, meeting minutes and other documents. With some iteration, the conceptual framework was reassessed and adjusted, and the material was searched for trends. After further iteration, the conceptual framework was further adapted and tested for the bulk of material, whereby the final model (figure 1) was created.

\section{Lean at HiTech Inc: Four types of non-human resistance}

In 2003, an initiative to introduce Lean at HiTech came from the corporate head of production. Coming from the automotive industry, he wanted to increase the performance of HiTech through Lean methods. After some discussion in the production management team, a decision was made to introduce Lean. From an ANT perspective, this can be seen as the overall action program. However, Lean cannot be introduced on its own; it needs to be broken down in bite-sized chunks in order to find a way into the organization (Benders and Slomp, 2009). Three methods were selected at the outset: Kanban, 5S and Visual Management (see descriptions below). These methods can be seen as subsets, or 'sub-programs', to the main action program (cf. Latour, 1987).

The lean initiative at HiTech has been far from a straightforward implementation exercise. Instead, we see a number of iterations in constructing, testing and redesigning the change initiative. These iterations have caused the change process to be prolonged and delayed and has led to large variation in the interpretation of Lean within the organization. The mediating role of organizational systems and artifacts interject them as a source of inertia and resistance in the organization. A change in organizational practice thereby becomes a question of changing organizational understanding as well as making sure that systems and artifacts are aligned with the proposed change. Through our analyses of these three action programs, we have identified four different types of non-human resistance. Below, we provide some examples of how these types come across in our case.

\section{Type I: Pre-existing anti-programs}

Every procedure that exists within an organization can be seen as an action program (Latour, 1992), and the surrounding networks that maintain them will usually be supported by a number of artifacts (Latour, 1986). In some cases, a proposed change will introduce an action program that contradicts current practice and its associated action program, resulting in a conflict between the two action programs. The existing practice can thereby be seen as an anti-program to the change initiative. Based on our case study, we will provide two examples of pre-existing anti-programs that resist HiTech's attempts to introduce a kanban system. 
Our first example concerns the logic behind the change. The governing principle behind the kanban method is just-in-time; production is triggered by a demand from the customer or downstream production operations (Shingo, 1984). However, the established accounting system is based on a diametrically opposite 'push' logic, where the financial results of a production unit are determined by the number of production hours.

If there is no demand from the customer, do we stand still? In our world, that costs millions a day. [...] We have, traditionally, been very focused on machine utilization, which is connected to our accounting system. (Production manager)

As discussed above, artifacts can represent certain ideas and influence behavior through their inscriptions. While the 'pull' logic and the principle of just-in-time production are inscribed in the kanban cards, the 'push' logic is inscribed in the accounting system. However, these two artifacts cannot determine the outcome of the change process directly, but simply support their respective action programs and their corresponding networks (Callon, 1986; Gherardi and Nicolini, 2000). The change process thereby becomes a trial of strength between the two action programs.

The Lean program is supported and encouraged by management at all levels at the HiTech site. By extension, the kanban program shares this support and is thereby associated with a quite large and strong network. However, the human actors in the kanban network are also enrolled in the same network as the accounting system, and this network stretches all the way to the corporation's head office.

Whereas the kanban method is supported by a belief in financial benefits of reducing lead time and inventory, the conflicting principle of the accounting system defines the method of measuring financial outcome. The accounting system thereby represents a much stronger action program that constitutes a major obstacle to applying the kanban method. Despite this power imbalance, the production manager is determined to introduce kanban. He believes that the long-term results will speak for themselves and that the 'push' principle eventually will be reassessed as the foundation for accounting. However, a large-scale implementation of the kanban method would be detrimental to the short-term financial outcome. Application of kanban from a pilot test was therefore deemed a more purposeful approach.

Our second example relates to this pilot test. The selected pilot area, the GV unit, manufactures components for the finished products at HiTech. At the start of the kanban project, there were four different variants of the finished HiTech products. Each of these requires about ten different GV components, resulting in approximately forty component variants in total. With the existing procedure, production is scheduled through production lists that show the orders that are available in the business system. The operators consult these lists - and their colleagues - to select the appropriate order to produce. While the idea is that kanban should replace the production lists as a control mechanism, these are allowed to coexist for some time for learning purposes. However, the coexistence of the two control systems has caused some confusion with the operators.

Right now, we don't have kanban for everything, just for one GV, and that complicates things. (...) But we still work in the traditional way, according to the list. So when the kanban drops in, we don't really know which one should go first. (Operator)

Surprisingly, not many people outside the core team seem to be familiar with the ambitions of introducing this new control method; only a limited number of people are involved.

Researcher: So, how are things going with kanban?

Operator: What is that? 
Researcher: You know, these cards that you are supposed to use.

Operator: Oh, those. I don't know. I am not involved in that.

In contrast to the kanban method, the established procedure for scheduling has a large network of supporting actors. The main artifacts that keep this network together are the production lists in which the action program is inscribed. Being much stronger, the lists easily win the tug of war against the kanban cards.

In these two examples we see how the idea of just-in-time is hindered by existing artifacts in the organization and the action programs they represent. As illustrated in figure 1, the planning lists and the accounting system influence people's behavior and reinforce their understanding of the organization. The new action program is not strong enough to break this pattern and, therefore, cements the status quo.

\section{Type II: Latent anti-programs}

According to the model proposed in figure 1, organizations are shaped by the interactions among practice, understanding and various non-human actors. Based upon these interactions, the organization has the potential to change in certain directions, but some change initiatives become more likely than others. The difficulties of coordinating large organizations may sometimes lead to conflicting initiatives, and an ongoing change initiative may be hindered by changes that have not yet been realized. We refer to such potential changes that may become obstacles to proposed changes as latent action programs.

For an example of latent programs, we return to the kanban initiative. The kanban system has been designed so that incoming material and finished goods have one dedicated shelf per component variant. Also, before the assembly operation, an inprocess buffer holds semi-finished components in order to compensate for differences in lead-time between operations. As downstream operations require components, such component is taken off the shelf for finished goods. An empty shelf triggers production, and incoming material is drawn from the corresponding shelf, thereby triggering replenishment. The finished products are assembled just a few meters from the GV unit; therefore, the kanban system can ensure tight communication between the two production units. Tight communication is critical to maintain just-in-time production. Through this design, the kanban system forms an alliance between GV and the assembly. This alliance is a double-edged sword; the alliance makes the network stronger but also allows the assembly to influence the system itself. When a decision was made to move the assembly to a different location, this synchronization was interrupted. The distance would make it impractical to collect and assemble the components one by one. Instead, they would be collected all at once; collection complicates the execution of the kanban system. The closest ally became a traitor that threatened the entire system.

Further, because of the large number of product variants, much effort has been made to carve out the necessary amount of shelf space. The system, then, becomes vulnerable to any changes in the product range. Being based on the product variants that exist, the kanban system becomes dependent on the design department, and when two new variants are introduced, the system is broken. In theory, new shelves for the new variants are possible, but new shelves are not feasible in practice.

In a sense, we have reached our pain threshold for material in the production flow, and we really do not have space for more. (Production supervisor)

This becomes the final nail in the kanban coffin; a complete redesign of the material control system is required. 
There will need to be a complete reinterpretation of kanban, because what we had in mind won't work with all product variants that we will have. So we need to sit down and create a new vision. (Floor manager)

The shelf system and the routines related to the kanban method are artifacts (per figure 1) that mediate the fundamental ideas behind the method. With an operational system, these artifacts would contribute to influence practice and reinforce the kanban idea. However, as the assembly moves and the new product variants are introduced, two fundamental conditions for the method are removed from the network and render the artifacts powerless. While these changes are unfortunate, they should not be particularly surprising. Such changes, and especially the introduction of new products, are natural parts of the business. Thus, the changes can be seen as action programs that were latent in the system, and the dependency that was designed into the system allowed them to blossom into full-blown anti-programs. Their negative impact could have been avoided with a more robust design of the system.

\section{Type III: Inadvertent creation of anti-programs}

Our first two types of non-human resistance are largely outside the control of the change agents. However, the change agents themselves may in fact create similar obstacles. When designing a new procedure, one may inadvertently create a structure that hinders the main idea behind the change. This newly produced structure may thereby constitute a third type of non-human resistance.

In our case, we see an example of this type of resistance in the introduction of $5 \mathrm{~S} /$ Housekeeping. The method aims to reduce the time spent looking for tools and materials by maintaining an orderly work environment (Chapman, 2005). Working with $5 \mathrm{~S}$ at HiTech involves two kinds of activities. First, and foremost, the idea is to tidy up the workplace and to standardize the placement of material and tools. This activity implies a great deal of cleaning and discussion among the personnel at each workstation. The progress of $5 \mathrm{~S}$ is then followed up on a monthly basis through audits led by the production manager and floor managers. During the audits, each workstation is evaluated based on eight criteria, all of which are rated on a five-grade scale. After the audit, any outstanding points are documented in an action list, and the eight evaluation criteria are visualized in a chart. Both of these are posted on a small whiteboard at each workstation. In order to support the operators' activities, a checklist for $5 \mathrm{~S}$ is also posted on the board.

All of these activities obviously take time. And all of the involved actors (both managers and operators) are already pressed for time to take care of other tasks. The number of evaluation criteria makes the audits very time consuming and eventually causes the audit procedure to seize entirely. One production supervisor explains.

We definitively do not have enough time to work with these issues, not even the Lean implementers. There are so many other things. We don't even have the time to do the audits to the extent we want to. (...) We are not so good at this because it takes a horrible amount of time.

The 'heavy backpack' of the 5S audits is an example of how anti-programs can inadvertently be inscribed in artifacts and cause resistance. The audits were a crucial part in emphasizing the method, and due to insufficient time to perform them as planned, attention towards the method decreases. This inattention produces a negative spiral, which is illustrated in figure 1; with decreased attention, the legitimacy of the method is weakened. In turn, operators lose interest and invest less energy in 5S. Thereby, the links in the 5S-network are gradually weakened until the network deteriorates, and there is no choice but to start over. 


\title{
Type IV: Ineffective non-humans
}

Just as a non-human actor can resist change through an inscribed anti-program, it can be an ally that strengthens the action program. However, efforts to enroll such non-humans in the network are not always successful. Like humans, non-humans can exert resistance by simply not contributing to the proposed change.

In exemplifying this fourth type of non-human resistance, we once again consider the $5 \mathrm{~S}$ initiative. Although the $5 \mathrm{~S}$ activities are performed to some extent, they never really manage to become institutionalized as routines. According to Feldman and Pentland, the problem lies in insufficient repetition.

\begin{abstract}
A pattern of actions that occurs only once is not a routine. Furthermore, even if a pattern of actions repeats, it needs to become recognizable as a pattern. In other words, a disconnected collection of performances does not constitute a routine without a corresponding ostensive category that makes the patterns coherent and recognizable as a routine. (Feldman and Pentland, 2003, p. 107)
\end{abstract}

As a consequence of this negative development, the artifacts lose their value; checklists are not used, and 5S-boards are used for other purposes (e.g. common notice board). A quite ironic example was encountered during a visit to one of the production units; the 5S-board for that unit lay on the floor, covered in dust and grease. To paraphrase Latour, the actors had literally let the token drop. From an ANT perspective, the ambition to fuel $5 \mathrm{~S}$ through audits is slightly off target. Using the principle of punctualization (Callon and Law, 1997), the audit procedure can be seen as an artifact in the $5 \mathrm{~S}$ network. The problem is that the audit does not have a natural place in the daily work with $5 \mathrm{~S}$. It is a form of meta-activity that is not directly related to the core idea of 5S. Similarly, the whiteboards are mainly used as auditing tools and do not really support any other $5 \mathrm{~S}$ activities.

In contrast to the clashes described above, there is no clear anti-program resisting the $5 \mathrm{~S}$ initiative. Instead, it is apparent that the artifacts connected to $5 \mathrm{~S}$ are largely ineffective. As we exhibit in figure 1, the artifacts are not aligned with the preferred practice or the underpinning ideas; they do not mediate the 'correct' ideas and do not contribute to the action program. Similarly to a human team member who does not contribute to the task at hand, this non-human member can be seen as a sort of passive resistance to change.

\section{A contrasting example}

A study of resistance can easily take on a negative tone and leave the reader with a sense of hopelessness (or critique toward the authors' negativity). We will, therefore, provide a positive example of how non-human actors can facilitate change. Our positive example, Visual Management (VM) is based on a set of interconnected daily meetings across the organization. Fifteen minutes is allocated to each meeting. Beginning with the shop floor, each production unit has a meeting during which non-conformances and current problems are discussed. If someone is able to solve the problem, $\mathrm{s} / \mathrm{he}$ is given the task to do so and report at the next meeting. Problems that cannot be solved directly are brought up to the next hierarchical organizational level, which will convene a meeting one half hour later. This principle is repeated all the way up to the top management team, who will decide what to do with issues that have not been solved at the lower levels.

Visual Management is held in a designated meeting area and always at the same time of day. The meeting area is dominated by a big whiteboard, which gives an overview of the main points of interest for each department. The production level board is divided into four sections, each of which is divided in sub-sections that illustrate the current status 
and any trends. The side of the board has an area allocated for any action points that are decided during the meetings. The VM board also serves as an agenda for the meeting. Going from left to right, each topic is covered, and any new information is recorded on the board. The production manager comments on the application of VM.

Visual management contains a bit of lean thinking. The purpose is to improve the information flow, reviewing what works and what doesn't. It has been very appreciated in the entire organization. I can tell you, it wasn't at first. But now, after a few years, it has become very powerful.

As opposed to kanban and 5S, Visual Management has been quite successful. Several explanations can be found for this success. An important part of the explanation is the enrollment of artifacts and structures that support and stabilize the method. The most important artifact is the VM board, which serves as meeting place, agenda, information source and action list. The entire action program is inscribed in this single artifact, making it an extremely powerful ally in the VM network.

The VM example reveals the power of alignment between the entities in figure 1; the combination of frequent repetition (daily meetings) and strong supporting artifacts reinforces the fundamental idea of the method. Every part of the model works together, creating a strong network and establishing the method as a new organizational routine that has quickly become a 'black box'.

\section{Conclusion}

Not only human beings resist organizational change. Organizational practice is deeply embedded in complex structures and systems that significantly influence human behavior. Together with the model in figure 1, the five examples above highlight the interaction that takes place between humans and non-humans within the organization. While a change initiative aims to transform a certain idea into organizational practice, the idea will be mediated, filtered and translated through the artifacts that exist within the boundaries of the organization, and the resulting practice will most likely differ from the original intent.

There are no emotions invested in the 'behavior' of non-human actors, and no ill will or wicked plan is behind their resistance to change. They simply 'act' in accordance with the action programs that they represent, and if those action programs happen to be in opposition to the proposed change, resistance will result.

Non-human actors resist change in a number of different ways. In this paper, we have provided four main types of resistance from non-human actors.

Table I Four types of resistance from non-human actors

\begin{tabular}{|c|c|c|}
\hline Type & $\begin{array}{c}\text { Non-human actors can } \\
\text { resist change through... }\end{array}$ & $\begin{array}{c}\text { Anti-programs can be in the } \\
\text { form of... }\end{array}$ \\
\hline I. & $\begin{array}{c}\text {...association with } \text { existing } \\
\text { anti-programs. }\end{array}$ & $\begin{array}{c}\text { Existing routines or principles } \\
\text { within the organization that } \\
\text { oppose the change initiative. }\end{array}$ \\
\hline II. & $\begin{array}{c}\text {...association with latent } \\
\text { anti-programs. }\end{array}$ & $\begin{array}{c}\text { Potential changes in the } \\
\text { organization that, if realized, } \\
\text { can have a negative impact on } \\
\text { the change initiative. }\end{array}$ \\
\hline III. & ...inadvertent creation of & $\begin{array}{c}\text { overly complex procedures } \\
\text { that take time away from the }\end{array}$ \\
\hline
\end{tabular}




\begin{tabular}{|c|c|c|}
\hline IV. & anti-programs. & main activities. \\
\hline $\begin{array}{c}\text {..insufficient contribution } \\
\text { to the action program. }\end{array}$ & $\begin{array}{c}\text { Procedures and artifacts that } \\
\text { do not provide sufficient } \\
\text { support for the main activities. }\end{array}$ \\
\hline
\end{tabular}

Non-human actors can resist change, but can also be powerful allies in organizational change processes. Just as they can be associated with action programs that contest a proposed change, they can be enrolled in networks that support the change (Latour, 1986). By anchoring organizational routines in various artifacts, non-human actors can facilitate change and contribute to stabilize routines. Such an alignment between organizational entities will increase the probability of succeeding with a change initiative.

Thus, our perspective on non-human resistance is not biased in favor of or in opposition to the proposed change (cf. Ford et al., 2008). We employ a purely descriptive/analytical perspective that illustrates how proposed change and non-human actors can constitute antagonistic forces and how artifacts can influence human behavior in directions that may easily be perceived as resistance. An interesting question is this: Whether human resistance can be explained through the systems that we work within? Perhaps nonhuman actors are the very reason behind human resistance to change.

While this paper has a sole focus on non-human resistance to change, we recognize the complexity of the matter and the fact that resistance is a multi-faceted phenomenon (cf. Jermier et al., 1994; Macrì et al., 2002). We do not contest previous research on resistance to change. We do, however, argue that existing theory is overly anthropocentric and that more attention should be directed towards the impact of organizational structures, systems and artifacts. In this paper, we propose a more elaborate perspective and argue that the inclusion of non-human actors in analyses of resistance can induce a number of novel studies in the future.

\section{References}

Akrich, M. and Latour, B. (1992), "A Summary of a Convenient Vocabulary for the Semiotics of Human and Nonhuman Assemblies", in Bijker, W.E. and Law, J. (Eds.), Shaping Technology/Building society, The MIT Press, Cambridge, pp. 259264.

Barley, S.R. (1990), "Images of imaging: Notes on doing longitudinal field work", Organization Science, Vol. 1 No. 3, pp. 220-247.

Beer, M. and Nohria, N. (2000), "Cracking the code of change", Harvard Business Review, Vol. 78 No. 3, pp. 133-141.

Benders, J. \& Slomp, J. (2009), "Struggling with solutions; a case study of using organisation concepts", International Journal of Production Research, Vol. 47 No. 18, pp. 5237-5243.

Callon, M. (1986), "Some elements of a sociology of translation: domestication of the scallops and the fisherman in St Brieuc Bay," in Law, J. (Ed.), Power, action, and belief: a new sociology of knowledge?, Routledge, London, pp. 196-223.

Callon, M. and Latour, B. (1981), "Unscrewing the big Leviathan: how actors macrostructure reality and how sociologists help them to do so", in Knorr-Cetina, K. and Cicourel, A.V. (Eds.), Advances in social theory and methodology, Routledge \& Kegan Paul, Boston, pp. 277-303. 
Callon, M. and Law, J. (1997), "After the Individual in Society: Lessons on Collectivity from Science, Technology and Society", The Canadian Journal of Sociology / Cahiers canadiens de sociologie, Vol. 22 No. 2, pp. 165-182.

Feldman, M.S. (2003), "A performative perspective on stability and change in organizational routines", Industrial and corporate change, Vol. 12 No. 4, pp. 727752.

Feldman, M.S. and Pentland, B.T. (2003), "Reconceptualizing Organizational Routines as a Source of Flexibility and Change", Administrative Science Quarterly, Vol. 48 No. 1, pp. 94-118.

Ford, J.D., Ford, L.W. and D'Amelio, A. (2008), "Resistance to change: The rest of the story", Academy of Management Review, Vol. 33 No. 2, pp. 362-377.

Ford, J.D., Ford, L.W. and McNamara, R.T. (2002), "Resistance and the background conversations of change", Journal of Organizational Change Management, Vol. 15 No. 2, pp. 105-121.

Gherardi, S. and Nicolini, D. (2000), "To transfer is to transform: the circulation of safety knowledge", Organization, Vol. 7 No. 2, pp. 329-348.

Hanseth, O. and Monteiro, E. (1997), "Inscribing behaviour in information infrastructure standards", Accounting, management and information technologies, Vol. 7 No. 4 , pp. 183-211.

Hutchins, E. (1993). Learning to navigate. In S. Chaiklin \& J. Lave (Eds.), Understanding practice: Perspectives on activity and context, Cambridge University Press, Cambridge, pp. 35-63.

Jermier, J.M., Knights, D. and Nord, W.R. (1994), Resistance and power in organizations, Routledge, London.

Latour, B. (1986), "The powers of association", in Law, J. (Ed.), Power, Action and Belief. A New Sociology of Knowledge?, Routledge and Kegan Paul, London, pp. 261-277.

Latour, B. (1987), Science in action, Harvard University Press, Cambridge.

Latour, B. (1992), "Technology is society made durable”, in Law, J. (Ed.), Sociology of Monsters: Essays on Power, Technology and Domination, Routledge, London, pp. 103-130.

Latour, B. (2005), Reassembling the social: An introduction to actor-network-theory, Oxford University Press, Oxford.

Latour, B. and Woolgar, S. (1986), Laboratory life: The construction of scientific facts, Princeton University Press, Princeton.

Lave, J., \& Wenger, E. (1991), Situated learning: Legitimate peripheral participation, Cambridge University Press, Cambridge.

LEI, Lean Enterprise Institute (2007), “New Survey: Middle Managers Are Biggest Obstacle to Lean Enterprise." Available at: www.lean.org/WhoWeAre/NewsArticleDocuments/lean_survey_07.pdf [Accessed August 29, 2011]

Macrì, D.M., Tagliaventi, M.R. and Bertolotti, F. (2002), "A grounded theory for resistance to change in a small organization", Journal of Organizational Change Management, Vol. 15 No. 3, pp. 292-310.

Miles, M.B. and Huberman, A.M. (1994), Qualitative data analysis: An Expanded Sourcebook, Sage, Thousand Oaks. 
Orlikowski, W.J. (2000), “Using technology and constituting structures: A practice lens for studying technology in organizations”, Organization Science, Vol. 11 No. 4, pp. 404-428.

Shingo, S. (1984), A Study of the Toyota Production System from an Industrial Engineering Viewpoint, Japan Management Association, Tokyo.

Silverman, D. (2006), Interpreting Qualitative data (third edition), Sage, London.

Suchman, L. A. (1987). Plans and Situated Actions: The problem of human-machine communication, Cambridge University Press, Cambridge.

Van de Ven, A.H. and Poole, M.S. (1990), "Methods for studying innovation development in the Minnesota Innovation Research Program," Organization Science, pp. 313335.

Van de Ven, A., Angle, H. L., \& Poole, M. S. (Eds.). (2000). Research on the Management of Innovations - the Minnesota Studies (2 ed.), Oxford University Press, New York.

Volkoff, O., Strong, D.M. and Elmes, M.B. (2007), "Technological embeddedness and organizational change”, Organization Science, Vol. 18 No. 5, pp. 832-848. 